\title{
Open to Feedback? Formal and Informal Recursivity in Creative Commons' Transnational Standard-Setting
}

\section{Article by an MPIfG researcher}

Leonhard Dobusch, Markus Lang, Sigrid Quack: Open to Feedback? Formal and Informal Recursivity in Creative Commons'

Transnational Standard-Setting. In: Global Policy 8(3), 353-363 (2017). Wiley-Blackwell

The original publication is available at the publisher's web site: https://doi.org/10.1111/1758-5899.12462
Leonhard Dobusch

Universität Innsbruck

Markus Lang

Universität Heidelberg

Sigrid Quack

Universität Duisburg-Essen

\section{Abstract}

In this article, we examine how non-membership organizations that claim stewardship over a transnational public or common good, such as the environmental or digital commons, develop combinations of formal and informal recursivity to develop and maintain regulatory conversations with their dispersed user communities. Based on a case study of Creative Commons, an organization that developed what have become the most widely used open licenses for digital content, we show how rhetorical openness to informal feedback from legitimacy communities in different sectors and countries can improve the feasibility and diffusion of standards. However, as long as the standard-setter's methods of making decisions on the basis of such feedback remains opaque, its communities are likely to raise accountability demands for more extensive ex post justifications.

\section{Policy Implications}

- Voluntary stewardship organizations that seek to exercise stewardship for a transnational public or common good have to balance the advantages and disadvantages of informal feedback in their standard-setting procedures.

- Insofar as such organizations combine informal but open feedback with formalized but opaque decision-making procedures, they have to address rising demands for ex post explanation and justification of their decisions.

- To counterbalance biases towards self-selection of the most active communities inherent in informal feedback, stewardship organizations should develop targeted measures to include groups affected by their standards that would otherwise likely remain absent from the feedback process.

In the debate on transnational economic governance, various forms of non-state standard-setting are often proposed in cases where international regulation is missing or perceived as inadequate (Bartley, 2007; Büthe and Mattli, 2011; Dobusch and Quack, 2013). However, standards are not only a tool for transnational governance, but also require governance of the process through which they are produced in order to ensure that they are accepted as effective and legitimate by those who are expected to follow them. Hence, for governance of continuously changing issues, particularly in fields driven by highly dynamic technological change, standard-setting and diffusion are a recursive activity (Braithwaite, 2002).

As highlighted in the introduction to this special section, recursive standard-setting varies significantly in terms of design and organization of membership, feedback channels and decision-making rules. Furthermore, to fully understand the existing variety of recursive standard-setting, it is also necessary to examine how users provide feedback and how standard-setters actually respond (see Malets and Quack, in this volume). This article contributes to one important but understudied dimension of organizing recursivity, which is the interplay of formal and informal feedback and decisionmaking processes in transnational standard-setting.

In the literature on recursivity in transnational governance, we find contributions that emphasize either formal or informal ways of organizing such iterative interaction processes between rule-setters and their addressees. In their work on the recursivity of global law, Halliday and Carruthers (2007, 2009) focused on how international organizations, professional associations and national governments participated in developing global legal norms for cross-border insolvency, 
implementing them domestically and revising them in the light of national reforms (Halliday and Carruthers, 2007, 2009). In a more recent contribution, Halliday and Shaffer (2015) develop the notion of transnational legal orders where transnational norms are produced in recognizable legal form by or in conjunction with private or civil society actors. In both cases, recursive feedback is predominantly organized through formalized channels for participation that are addressed to clearly specified actor categories.

At the other end of the spectrum, Calliess and Zumbansen's (2010) concept of rough consensus and running code (RCRC) draws on the informal processes involving a rather diffuse and weakly bounded community of internet users through which the Internet Engineering Task Force developed technical standards for internet governance (see, for further examples, Gasser et al., 2015). In this process, the chair of a committee can pronounce a rough consensus about intermediary or final results that are then put to a test with internet users. Calliess and Zumbansen apply this concept to the evolution of consumer and corporate governance contracts in transnational private law.

Both approaches highlight the need to consider feedback from potentially diffuse audiences of users in transnational standard-setting. While both alert us to mixed public-private and dynamic norm creation, the global and transnational law approach emphasizes formal processes of norm creation, while the RCRC approach emphasizes informal ones. However, formal and informal recursivity do not seem to be exclusive or exhaustive categories. A growing literature on transnational standard-setters, including some of the contributions in this special section, points towards complex combinations of formal and informal channels for organizing feedback across the public-private divide (Bartley, 2011; Botzem and Dobusch, 2012; Brunsson and Jacobsson, 2000; Ortmann, 2010). Among voluntary standard-setters, the mix of informal and formal procedures for recursivity seems to vary considerably depending on whether standards are publicly recognized or not, and whether the standard-setter is a membership or non-membership organization (Anheier and Themudo, 2002; Dingwerth, 2008).

In this context, stewardship organizations that produce and maintain public or common goods face particular challenges in organizing feedback processes (Rose, 2014). Like all standard-setting organizations, they depend on the voluntary adoption of their standards. While membership-based organizations can manage their legitimacy relations with potential users by providing them with well-defined voting and consultation rights, non-membership organizations by design have chosen a different path that requires them to develop alternative means of interacting with dispersed groups of (potential) users to gain legitimacy for their standards.

This paper analyzes how transnational non-membership organizations catering for public or common goods organize and manage recursive standard-setting in relation to their globally dispersed and diffuse user groups. It does so through an empirical case study of Creative Commons (CC), investigating how a non-membership organization evolved as the producer of a set of alternative copyright licenses with the aim of creating a commons of digital goods, and how it collects and responds to feedback from its potential users. The case of CC is of particular theoretical interest because it allows us to study formal and informal feedback in situations of technological and regulatory uncertainty.

\section{Analytical Framework}

Under conditions of polycentric governance without clear hierarchy and distributed agency (Black, 2002), transnational standard-setters depend on the voluntary acceptance of their standards by as many users as possible in order to gain a wide diffusion. These rules will gain regulatory impact only if potential users accept them as appropriate. Therefore, standard-setters must seek to build legitimacy among heterogeneous groups, including other regulators and diverse groups of potential users (Black, 2008; Djelic and Sahlin-Andersson, 2006; Hahn and Weidtmann, 2016). Suchman's (1995) distinction between pragmatic, moral and cognitive legitimacy provides a useful heuristic to study how such legitimacy is constructed and maintained. Whereas pragmatic legitimacy rests on alterable views about the effectiveness and usefulness of a standard, moral legitimacy reflects more resilient normative assessments among user groups that the rules in place are appropriate. Cognitive legitimacy is based on the assumption that things cannot be any other way. Suchman's approach to legitimacy differs from a purely normative one insofar as it highlights the relevance of people's perceptions of the rightfulness and appropriateness of public and private authority for their acceptance and support of rules.

One way to analyze the interactions between standard-setters and their potential users over the appropriateness of their rules and procedures is to study the regulatory conversations that evolve between them. As Black (2002, pp. 170f.) observes, regulation in polycentric transnational regimes is not simply a matter of control and command, but involves complex regulatory conversations about the definition of problems, diagnoses and regulatory solutions. The importance of such symbolic interactions has also been recognized by other authors, such as Halliday and Carruthers (2007) in their study of 'diagnostic struggles' and Zumbansen and Calliess (2010) in their focus on the dynamics of consensus building in transnational private law. According to Black, regulatory conversations involve communications regarding the operation of a given regulatory system between regulators, the regulated and others involved in the regulatory process.

The organization of iterative feedback processes in which users can voice their experiences and problems with standards is a key technique of regulation. This technique can fulfill different functions in the standard-setting process. First, it can help to address ambiguities of meaning in written standards in relation to their practical application in specific contexts by developing shared understandings. Second, it is a means of managing possible contradictions that may arise in the process of implementing standards. Third, it facilitates the adaptation of standards to unforeseeable changes in the technical, economic, social or political 
environment. Last but not least, it enables transnational standard-setters to build and develop their legitimacy communities.

In this paper, we apply the concept of regulatory conversations to recursive transnational standard setting. Following Malets and Quack's framework (see introduction to special section) we examine, first, the standard-setter's design and organization of formal and informal channels for feedback; second, the actual usage of these channels by potential users and legitimacy communities; and third, the standardsetter's responsiveness to such feedback as part of an ongoing regulatory conversation. This approach allows us to analyze how standard-setters and users validate their legitimacy claims and beliefs in an ongoing discourse dealing with regulatory uncertainty and a changing application context.

Depending on the organizational form that standard-setters choose during their formation, they have different options regarding how to organize feedback processes addressing potential and existing legitimacy communities. As Anheier and Themudo (2002) argue, membership-based non-governmental organizations typically have a more developed set of formalized rules that regulate the right to information, consultation, account-giving and voting in standard-setting matters than their supporter-based counterparts. Anheier and Themudo further argue that accountability remains a problem among the large number of supporter-based global NGOs, many of which claim a stewardship role and/or develop standards. At the same time, they point out that there are various channels through which supporters might nevertheless gain influence and 'quasi-ownership' of such an organization. So far, however, we lack systematic empirical research on how non-membership organizations generate feedback from their supporting communities through informal or formal channels.

In this paper, we examine how non-membership organizations that act as standard-setters collect and process feedback from their respective legitimacy communities via both formal and informal means. Formal feedback is based upon explicitly codified procedures that are specified in written documents, such as classifications of contributors, the timing and duration of consultation periods and other rules of due process. As a consequence, formalized feedback processes exhibit greater degrees of transparency as a basis for accountability relations, albeit at the price of potentially foreclosing conflictual spaces (Garsten and Jacobsson, 2011). In informal feedback, in contrast, such a codification of rules is largely absent. Still, informal feedback involves organizing.

Standard-setters have different options regarding how to organize such informal feedback, which is likely to shape the content and dynamic of regulatory conversations. First, whether a standard-setter presents itself as rhetorically open to a wide range of feedback from a relatively unspecified range of potential users and audiences or as more focused on feedback from specifically circumscribed groups is likely to shape the range of potential participants involved in feedback. Moreover, the modus operandi used (e.g. a public mailing list versus private e-mail conversations) may generate feedback from a wider audience or more selective groups. Second, whether the standard-setter steers the timing of its regulatory conversations in an open-ended manner or according to deadlines, together with the frequency with which it requests informal feedback, is likely to impact the use of such informal channels for feedback. Important tradeoffs exist between each of these dimensions, from the perspective of both standard-setters and legitimacy communities. For example, faced with suggestions and criticism from members of legitimacy communities, standard-setters could reasonably be expected to either decrease the frequency of recursive cycles or continuously balance conflicting demands by routinizing their regulatory response. Reducing the number of adjustments is desirable because it minimizes incompatibilities between various standard versions, increases effectiveness and may enhance pragmatic legitimacy (see also Dulong de Rosnay, 2009). But the routinization of adaptation processes might also be perceived as undercutting deliberation and evoke negative responses from the community.

Once established, formal and informal feedback processes can develop a life of their own. For example, in the early stages, standard-setters might inaugurate informal feedback processes to gain diverse knowledge from different user communities to improve the effectiveness of their standards and thereby enhance their pragmatic legitimacy. Over time, the balance may change as legitimacy communities become established and develop their own internal rationales that might lead them to challenge the standard-setters' legitimacy claims on normative grounds, demanding more information, accountability or participation in formal decision-making procedures. In the following analysis, we therefore pursue a longitudinal analysis of a standard-setter's organization of formal and informal feedback channels, user groups' usage of these channels and the standard-setter's responsiveness to such feedback. This analysis reveals how regulatory conversations between standard-setters and their legitimacy communities evolve over time.

\section{The Case of Creative Commons}

CC was founded by legal scholars and copyright activists with the aim of developing open licenses for digital content (text, music, video, etc.) as a reaction to new technological opportunities created by the digital revolution and positioned against traditional all-rights-reserved approaches to copyright. It was initiated by a group of US academics specialized in intellectual property, internet law and new media with financial support from Stanford University and the Center for the Public Domain. CC was incorporated as a charitable organization under Massachusetts law in 2001. Funding comes from a wide range of academic institutions, corporate and private sponsors and other NGOs (Van Eechoud and Van der Wal 2008, p. 30). The organization is governed by a board of directors (whose size has increased over time), a CEO and a corporate secretary. As of October 2016, CC had a staff of 14 part- and full-time employees and six regional coordinators (CC, 2016). 
The goal of CC is to 'build a layer of reasonable, flexible copyright in the face of increasingly restrictive default rules' (CC, n.d.a). In a world where access to online available works such as academic and educational texts, websites, databases, music, photography and film is increasingly subject to extended national and global intellectual property rights laws and treaties (Archibugi and Filipetti, 2010), CC aims to provide tools that allow people to license their works for free for certain uses while retaining their copyright, or to dedicate them fully to the public domain. To this end, CC has developed modularized web-based licensing tools, using 'private rights to create public goods'. Overall, CC has been rather successful in developing and promoting its set of licenses: by 2013, over a decade after it published its first set of licenses, CC had not only repeatedly revised its core set of licenses, but also become the standard for open content licensing beyond software with prominent adopters such as Wikipedia and YouTube.

CC has three characteristics that are representative of a broader range of standard-setting organizations. First, it is a stewardship organization that claims to provide licenses in order to create a public good, yet is incorporated as a nonmembership organization. In the case of CC, this means guaranteeing legally solid, technically sustainable and globally applicable licenses that respond to users' needs. Given its lack of membership, however, the organization has to find other ways than classic membership votes to incorporate feedback from its legitimacy communities. Second, CC is a truly transnational organizational network. Within only five years of its foundation, and despite limited financial resources, it had already built a transnational network of affiliate organizations in over 50 jurisdictions (Dobusch and Quack, 2010; Morando, 2014). This network requires CC to interact with and mediate between numerous groups of experts and activists from many countries and fields, including education, music and cultural heritage organizations, around the world. Hence, as a stewardship organization it has to address a range of highly diverse legitimacy communities. Third, from early on CC used a wide range of online media to build, sustain and interact with its legitimacy communities. As a consequence, the case of CC allows us to track the incremental emergence of a variety of informal and more formal channels of communication between the organization's headquarters, its affiliates in different national jurisdictions and multiple developer, activist and user communities. Taking these three points together, an in-depth study of CC promises to provide theoretical insights (Flyvbjerg, 2006; Yin, 1994) into the use and effects of such tools for standard-setting organizations in a wide range of other fields.

We investigate recursive standard-setting processes between CC headquarters and its emerging legitimacy communities with a focus on three separate but interconnected dimensions of organized but largely informal feedback: (1) the adaptation of global standards to local expectations (in technical terms, 'porting' the license to different jurisdictions); (2) learning from previous interactions between headquarters and legitimacy communities in the course of versioning licenses; and (3) engagement in an ongoing conversation about interpretations between standard-setters and users. In our analysis, we combine two types of empirical data: publicly available jurisdictional and transnational mailing lists that reveal the interactions between CC representatives and user communities; and 52 semi-structured interviews conducted by the first author with members of CC headquarters (5) and representatives of CC affiliate organizations in various countries (47) to inquire into CC's decision-making procedures (Table 1). The comparison of the two data sources allows us to gain an in-depth view of how regulatory conversations have shaped the development of licensing standards over time, across the global and local levels and between standardization and implementation.

\section{License porting}

While CC has always aimed to provide a global commons of digital goods, copyright varies substantially across jurisdictions. Making CC's licenses globally applicable therefore required recursive feedback cycles with local copyright experts in order to help ensure that the licenses would be upheld in their respective national courts. The strategy initially pursued by CC to reach this goal was one of adaptation. After the launch of the first generic set of license modules in December 2002, CC started to adapt ('port') its licenses to over 70 different local jurisdictions; the main goal was to secure maximum uniformity in terms of legal certainty. This porting process was supported by copyright lawyers in different jurisdictions, most of whom were inspired

Table 1. Dimensions and data sources in the study of Creative Commons

(1) License porting

Data sources

Time period
- Interviews with CC officials and legal affiliate partners

-Public mailing lists

(UK, Germany,

Brazil, transnational)

2004-2008

(2) License versioning

(3) License interpretation

- Online archival data

(e.g. CC wiki)

- Public mailing lists

-Follow-up interviews

2002-2016
- Interviews with CC officials and legal affiliate partners

-Public mailing-lists (transnational, Germany) - Survey data 2003-2010 
by the free/open source software movement and had personal ties to some of the US founders of CC, contacting the organization to obtain the right to transpose the licenses to different national legal systems. In 2003, CC opened an 'iCommons' office in Berlin to coordinate these volunteers from different countries. In contrast to the literal translations of licenses known in the world of free/open source software licensing, porting CC licenses also involved legal adaptations:

I understand the translation effort of the CC licenses as not only translating but also adapting them to the legal framework of different countries. If this is right, it is quite different from the unofficial translations of the GPL and similar texts. (Mailing list, 2004)

Formally, a so-called 'legal project lead' was appointed to serve as an affiliate organization in each country and provide legal expertise - either directly or via local partners. Legal project leads were regularly complemented with 'public project leads' with the main task of activist and outreach work. Restrictions on these project leads' role as affiliates relate exclusively to the use of $\mathrm{CC}$ as a trademark and formal license porting processes, both of which are set out in a short Memorandum of Understanding (MoU) (CC, 2013). Otherwise, affiliates have to find their own funding and are highly autonomous in their work. After signing an MoU, local legal affiliate partners translated and legally adapted the licenses to the requirements of their jurisdiction. These drafts were translated back into English, reviewed by CC headquarters and, if approved, published with a public call for comments. After a public review period, the affiliate partner revised the draft version, which was then officially launched after approval by the CC headquarters. This process was repeated whenever $C C$ headquarters published a new version of the license.

Within this formalized framework, informal feedback was collected via public mailing lists that were open to whoever was interested in participating. Such mailing lists were set up by the project lead in each jurisdiction and complemented by a transnational mailing list moderated by CC headquarters. Calls for comments on license drafts were typically open ended, and feedback was incorporated at the discretion of the legal project leads and CC staff. While mailing lists quickly died away in some jurisdictions, in others they developed a life of their own that went far beyond commenting on license drafts during the porting process. Contributions came from a wide range of people, including users - such as artists, librarians and bloggers experts and activists in the field of copyright, the project leads and CC headquarters staff, but typically a large number of posts were generated by a relatively small number of contributors, as is common for online discussions in general (see, for example, Guo et al., 2009). In addition to the public mailing lists, other informal feedback channels operated through a non-public mailing list, regular meetings and personal conversations between the project leads and staff from CC headquarters.
Based on a comparative analysis of public mailing lists in Brazil, Germany and the UK (England and Wales) - three early adopting jurisdictions with distinct copyright law regimes - and complementary expert interviews, four functions of informal feedback can be distinguished: improving license drafts, identifying broader implementation problems, discussing strategy and building community. While the prevalence of each of these functions varied between jurisdictional contexts, all of them were present in each of them.

While comments relating specifically to the porting process, including suggestions for the improvement of published drafts, were frequent, they were not the primary topic discussed on any of the lists, partly because license drafts had been elaborated by project leads with a smaller circle of copyright lawyers and activists in preceding discussions. Still some porting issues were brought up on public mailing lists, which influenced subsequent decisions. Examples are early debates on moral rights on the UK mailing list, which laid the ground for their exclusion from subsequent CC licenses; and discussions on the differences between English and Scottish copyright law, which paved the way for a separate Scottish porting project (Lang, 2011). Overall, however, informal feedback on mailing lists often went beyond a specific call for comments on a given jurisdictional porting project.

In terms of numbers of contributors related to a given topic, broader implementation problems were of higher importance on all three jurisdictional mailing lists than issues relating to the porting process. However, discussions about CC's strategy were an even more central topic on all three mailing lists, and contributors often made normative arguments regarding how copyright problems should be addressed. In Brazil, for example, the mailing list at times served as a very lively public discussion platform on the government-initiated reform of copyright law. Elsewhere, strategic debates revolved around whether CC should take a more revolutionary or reformist stance, whether diverse or standardized licenses were preferable and alternative ways of achieving compatibility with existing open source licenses.

Finally, by allowing contributors to articulate their views on what was considered acceptable or not, debates on public mailing lists added to the emergence of a legitimacy community. To be clear, beyond public mailing lists, interactions between legal project leads and subsequently introduced public leads across jurisdictions, as well as personal interactions between community members and representatives of CC headquarters at and between conferences such as global iSummits, were constitutive of CC's legitimacy community. While not everybody agreed on all issues, and while topics such as noncommercial licenses remained controversial (see below), a consensus emerged among those who considered CC a worthwhile project in attempts to reform the copyright landscape. Nonetheless, community building resulted in new challenges for CC's internal governance, since not everyone was willing to accept the organization's discretionary decision-making. Attempts to restructure legal infrastructure and activism into two 
Table 2. Overview of selected features of Creative Commons license versions, adapted and shortened from CC (2017).

\begin{tabular}{|c|c|c|c|c|c|}
\hline License Suite Version & 1.0 & 2.0 & 2.5 & 3.0 & 4.0 \\
\hline Year & 2002 & 2004 & 2005 & 2007 & 2013 \\
\hline Nomenclature (for unported licenses) & $\begin{array}{r}\text { Generic } \\
\text { license }\end{array}$ & $\begin{array}{r}\text { Generic } \\
\text { license }\end{array}$ & $\begin{array}{l}\text { Generic } \\
\text { license }\end{array}$ & $\begin{array}{l}\text { International } \\
\text { (unported) } \\
\text { license }\end{array}$ & $\begin{array}{l}\text { International } \\
\text { License }\end{array}$ \\
\hline $\begin{array}{l}\text { Technological measures by users of } \\
\text { CC licensed works prohibited }\end{array}$ & Yes & Yes & Yes & Yes & Yes \\
\hline Attribution required & $\begin{array}{l}\text { Not all } \\
\text { licenses }\end{array}$ & Yes & Yes & Yes & Yes \\
\hline $\begin{array}{l}\text { Waiver of express reservation of right } \\
\text { by collecting society to collect royalty }\end{array}$ & $\begin{array}{l}\text { Not } \\
\text { addressed }\end{array}$ & $\begin{array}{l}\text { Yes where } \\
\text { possible }\end{array}$ & $\begin{array}{l}\text { Yes where } \\
\text { possible }\end{array}$ & $\begin{array}{l}\text { Yes where } \\
\text { possible }\end{array}$ & $\begin{array}{l}\text { Yes where } \\
\text { possible }\end{array}$ \\
\hline $\begin{array}{l}\text { Representations and warranties } \\
\text { by licensor included }\end{array}$ & Yes & No & No & No & No \\
\hline 'No endorsement' clause included & No & No & No & Yes & Yes \\
\hline Personal/moral rights & $\begin{array}{l}\text { Not } \\
\text { addressed }\end{array}$ & $\begin{array}{l}\text { Not } \\
\text { addressed }\end{array}$ & $\begin{array}{l}\text { Not } \\
\text { addressed }\end{array}$ & Varied & $\begin{array}{l}\text { Waived } / \text { not } \\
\text { asserted }\end{array}$ \\
\hline $\begin{array}{l}\text { Adaptations (if allowed) } \\
\text { must be marked as such }\end{array}$ & No & No & No & Yes & Yes \\
\hline Definition of 'NonCommercial' (unchanged) & Yes & Yes & Yes & Yes & Yes \\
\hline $\begin{array}{l}\text { Sui generis rights in databases are waived } \\
\text { for uses that do not implicate copyright }\end{array}$ & No & No & No & EU ports only & Yes \\
\hline $\begin{array}{l}\text { License conditions apply to sui } \\
\text { generis database rights }\end{array}$ & No & Few ports only & Few ports only & No & Yes \\
\hline
\end{tabular}

separate organizational units in 2005 were unsuccessful (Dobusch and Quack, 2010) and did not resolve existing tensions between continued calls for informal feedback and what was perceived as non-transparent decision-making regarding which feedback was considered and which was not. For instance, a project lead of a Northern European country complained about non-transparent decision-making: 'I don't feel like I'm part of their organization [...], which sounds strange, as I'm a Creative Commons lead' (interview with CC affiliate lead, 2009).

Overall, the interplay of informal and formal processes during the first years of CC's porting of the global license went beyond 'rough consensus and running code'. Informal feedback certainly provided important input for revising specific drafts and identifiying broader problems that helped CC integrate learning from local experience into subsequent versions of its licenses. At the same time, informal regulatory conversations on mailing lists, summit meetings and private conversations contributed significantly to the formation of a legitimacy community. Once this community was in place, discussions among its members came hand in hand with dissatisfaction over and criticism of the non-transparent decision-making by parts of the community. This situation created a need for CC to provide greater ex post explanation of its decisions.

\section{License versioning}

As a license steward, one of the main tasks of CC is to continuously monitor whether its set of licenses continues to meet the needs of current and potential users. This goal is pursued through recurrent calls for feedback from (potential) users and jurisdictional project leads regarding whether technological or legal changes demand corresponding changes in CC licenses. To date, there have been four versioning processes. These versioning processes have constituted 'recursive episodes' (Halliday and Caruthers, 2007 , p. 1148) that have taken place in a formal framework similar to the one used in porting (Table 2). Based on informal consultations, CC headquarters publishes a draft of the revised licenses and invites the interested public to comment on it. Each review period is concluded with the publication of either another draft, followed by another review period, or the new version of the license. Again, decisions on which changes are eventually included are discretionary and only justified after the fact by CC headquarters, i.e. the CEO and the legal counsel. Three developments stand out from the four versioning cycles: the integration of informal local feedback beyond jurisdictions; the move from ported to international licenses; and the further development of ex post justifications for decisions.

As mentioned above, informal feedback collected during jurisdictional porting processes by project leads and mailing lists revealed manifold information about potential conflicts between jurisdictional law and the implementation of CC licenses. Many of these problems were not unique to one jurisdiction and called for a more general approach. Many of the substantial revisions of CC licenses during the four recursive episodes depicted in Table 3 are responses to such broader implementation problems. For example, version 2.0 addressed problems with collecting societies that had been mentioned earlier on the German mailing list, followed by 
Table 3. Timeline and duration of Creative Commons versioning processes

\begin{tabular}{llllll}
\hline $\begin{array}{l}\text { License } \\
\text { version }\end{array}$ & $\begin{array}{l}\text { Call for } \\
\text { comments }\end{array}$ & $\begin{array}{l}\text { 2nd call for } \\
\text { comments }\end{array}$ & $\begin{array}{l}\text { 3rd call for } \\
\text { comments }\end{array}$ & Launch & $\begin{array}{l}\text { Period until } \\
\text { next revision }\end{array}$ \\
\hline 1.0 & - & - & - & $16-$ Dec-2002 & - Review period \\
2.0 & 26-Jan-2004 & - & - & $24-$ May-2004 & 4 months \\
2.5 & 21-May-2005 & - & - & 7-Jun-2005 & 9 days \\
3.0 & 09-Aug-2006 & 30-Oct-2006 & - & 23-Feb-2007 & 7 months \\
4.0 & 11-Nov-2011 & 1-Aug-2012 & 15-Feb-2013 & 25-Nov-2013 & 24 months \\
\hline
\end{tabular}

other jurisdictions. The application of CC licenses to databases was made explicit in version 4.0, following related debates in several jurisdictions.

A more drastic change occurred when the CC board decided to abandon the porting process in favor of issuing international versions of its licenses that could be independent of the jurisdiction. The first steps in this direction were undertaken with version 3.0, while full internationalization was realized with version 4.0. The background to this decision was that, because each new license version required another porting process in all jurisdictions with ported licenses, members of the CC board debated whether to continue with their 'porting experiment' (Dobusch, 2013). Specifically, in smaller jurisdictions with fewer copyright lawyers, porting is a difficult process and often takes a long time - if it ever happens. At the same time, based on experiences with more than 70 jurisdictions to which previous CC licenses had been ported, the CC board felt that its community had the knowledge to develop a unified approach to copyright issues that are regulated in distinct ways in different jurisdictions, such as the moral right to the integrity of the work or database rights. Thus, recursivity based on informal feedback between the license steward and key legitimacy communities, such as mailing list contributors, project leads and local copyright lawyers, enabled a more generic strategy to licensing.

Finally, there has been a decrease in the frequency of recursive cycles, along with substantial increases in the length of recursive episodes and the depth of explanations demanded from CC officials regarding proposals for license changes. As documented in Table 3, the period between revisions increased from 18 and 12 months in the first two versioning cycles to 32 and 79 months in the last two cycles. At the same time, the review period following a call for comments increased from four months for version 2.0 to seven months for version 3, and to 24 months for version 4 (leaving aside the intermittent version 2.5), partly because a second and third call for comments was issued in the last two rounds.

The following two quotes illustrate how the need for CC to legitimize such decisions by offering an explanation for them seems to have increased over time. In explaining changes in version 2.0, Glenn Otis Brown, CC's executive director at the time, simply stated that an often requested change had not been made, without explaining the decision at length:
After much very strong and eloquent argument from our readers and supporters, and notwithstanding the increased flexibility of Share Alike in the iCommons context, we decided not to make the BY-NC-SA and plain BY-SA licenses compatible. (CC/Brown, 2004)

In 2013, CC Legal Counsel Kat Walsh devoted a whole blog post to justifying having turned down a single proposal for renaming the NonCommercial (NC) license module. Before detailing the reasons for the decision, Walsh stated the following:

We received a lot of valuable feedback on the Commercial Rights Reserved proposal, and ultimately, there were many strong arguments both for and against it. One point that was broadly recognized, however, was that a change of the license name would be difficult to communicate and require a fair amount of time, effort, and in some cases expense, and a change would have to justify this cost. After evaluating the feedback, we believe that the case for changing the name was not strong enough for this. (CC/Walsh, 2013)

In sum, informal feedback generated by key groups of its legitimacy community enabled CC to learn from experience and build a unique commons of copyright knowledge in a large number of jurisdictions, even though the organization's decision-makers used these inputs selectively and in ways that were not always transparent to those who had generated them. Hence, informal feedback helped the organization improve the feasibility of its licenses and diffuse them widely to a broad range of users, while it also increasingly raised questions about the accountability of the organization's leadership to its emerging legitimacy communities.

\section{License Interpretation}

We can also observe a shift in how CC and its community dealt with the indeterminacy of transnational rules in discussions about license porting and versioning. While the first five years were characterized by attempts to translate transnational standards into legally robust national concepts and local languages, around 2006 the diversity of licenses and understandings provoked a turn towards unified 
international licenses. These unified licenses did not resolve the problem of competing rule interpretations among user communities, however. For a long period, the organization focused on attempts to work towards globally shared interpretations of its standards through mailing lists, explanatory documents by CC headquarters and even a large license user survey (CC, 2009). It was the results of the latter that led CC to shift towards a more pluralistic approach aimed at fostering compatible rather than shared understandings among various sub-communities. In other words, CC began to accept different interpretations as long as they were compatible enough not to create conflicts among license users.

These developments can be illustrated best by examining controversies around the NC license module, which preserves commercial usage rights. The main motivation for offering the NC module was to enable business models that are compatible with file sharing, remixing and other forms of noncommercial use. In the past, the NC module was one of the most adopted optional license modules, but it has also been the most controversial because users understood it in very different ways. While some user communities saw $\mathrm{NC}$ licenses as a tool to preserve rights for commercial use, other communities - including, for example, contributors to the CC-licensed Wikipedia - voiced concerns about the fragmentation of alternative licensing standards. Insofar as licensees retain commercial rights to content, this content cannot be published on platforms such as Wikipedia that allow the commercial use of texts, pictures, films and audio files. Therefore, since the launch of its first version in 2002, the NC module has been subject to controversies regarding its regulatory uncertainty, since users have tended to understand it in different ways (Dobusch and Kapeller, 2012).

The core clause of this module has not been changed since version 1.0 of the license and reads as follows in the English 'generic license':

You may not exercise any of the rights granted to You in Section 3 above in any manner that is primarily intended for or directed toward commercial advantage or private monetary compensation. The exchange of the Work for other copyrighted works by means of digital file-sharing or otherwise shall not be considered to be intended for or directed toward commercial advantage or private monetary compensation, provided there is no payment of any monetary compensation in connection with the exchange of copyrighted works. (CC, 2002)

This definition requires users of CC licenses - i.e. both licensors and licensees - to agree on where to draw the line between commercial and noncommercial use. While in many cases, such as the use of works in advertising, this distinction is straightforward, there are also fringe cases, such as the following, that were reported back to CC mostly via mailing-list inquiries:

Hello, I am interested in creative commons licenses, but I have a few questions concerning the definition of noncommercial use? Here are a few examples that are unclear to me (assume all music files are covered under a Noncommercial CC license); a.) A website distributes many music files, which is the main focus to the site. The site makes money on advertising. b.) A website distributes many music files, which is the main focus to the site. The site is subscription only. [c].) A website distributes many music files, which is only one part of the site (it also offers, news, e-mail, I don't know, whatever). The site is subscription only. d.) I burn a CD full of music files and ask for $\$ 2$ for my time and material costs. (much like selling a copy of Linux[.]) e.) If I make the song, and distribute it, and license it under the CC noncommercial, would there be any problem with ME selling it as I see fit? Understanding that other people could legally give it away? (Inquiry on a public mailing list, March 2003)

CC headquarters first tried to clarify the 'actual' meaning of the NC module by collecting and incorporating feedback from users through mailing lists and by means of official explanations on its website and in 'Best Practice Guidelines' published in 2006 (CC, 2006). After this approach failed, officials at CC headquarters considered another three options - changing the license, accepting the current level of uncertainty and discarding the NC module all together:

One is that there is a large number of people who don't understand why Creative Commons doesn't not just declare 'This is what it means. Take it or leave it' [laughs]. Like, they just want certainty. There is another group of people who say we will never figure it out, we should just stop worrying about it or we should just do away with the license entirely, because we are never gonna define it right. (Interview with CC employee, 2008)

To provide a broader knowledge base on which to make a decision on this issue, in 2009 CC commissioned the license user survey "Defining "Noncommercial": A Study of How the Online Population Understands "Noncommercial Use,"' with over 2,000 respondents (CC, 2009). One of the core results of the study was that the different interpretations of 'noncommercial' prevalent among different communities of license users did not necessarily hinder license adoption and were mostly compatible (see Dobusch and Kapeller, 2012).

The latest round of discussions around the NC module took place in the course of the 4.0 versioning process, where various options for addressing NC were under consideration. However, after intense debates - for example, on the CC wiki (CC, n.d.b) and at the CC Global Summit 2011 in Warsaw (Dobusch, 2013), all the proposals were discarded by CC headquarters in a public statement entitled 'Commercial Rights Reserved proposal outcome: no change' (CC/Walsh, 2013).

\section{Advantages and disadvantages of informality}

The analysis shows that license porting, license versioning and license interpretation follow recursive standard-setting processes that include significant informal methods of 
Table 4. Formal and informal feedback processes

(1) License porting

All users of CC licenses outside the U.S.

Relevant user communities

Formal procedures

Formal agreements with

local affiliate partners

Publishing of draft versions

Call for comments

Internal decision making on which

suggestions to incorporate

Informal

procedures
Comments are collected via mailing lists Conversations between headquarters and legal affiliate leads at CC summits
(2) License versioning

All users of CC licenses

(musicians, writers, scientists, etc.)

Publishing of draft versions

Call for comments

Internal decision making on

which suggestions to incorporate

Comments are collected via mailing lists

Conversations between headquarters and legal affiliate leads at CC summits
(3) License interpretation

Users of licenses who preserve rights in commercial use and users of respectively licensed works; free license advocates

Best Practice Guidelines were published in 2006 to clarify the definition

Commissioning of the survey 'Defining "Noncommercial"' (2009) Internal decision making on the development of the NonCommercial licensing module Comments are collected via mailing lists

CC Wiki

Debates at CC Summit (2012) collecting and integrating feedback from different communities of dispersed users (Table 4). Still, there is also some variation. Porting is the most highly formalized of all three processes, as it requires checks on different levels. And CC headquarters have been less responsive to informal feedback regarding the $\mathrm{NC}$ module than they were to feedback regarding versioning and porting.

One of the most interesting facets of CC compared to more traditional national law settings is the 'official' character of its informal recursivity. While informal recursivity may and mostly will also play a role in the course of regulatory processes, it is regularly considered to covertly subvert formal rules (for example via lobbying). While this informality is not 'hidden' but acknowledged in the case of CC, decisionmaking opacity and the self-selection of participants might nevertheless yield exclusionary effects (Freeman, 1972-73).

These exclusionary effects can also be seen when we compare the mix of formal and informal stewardship processes used by CC with those of the membership organizations studied elsewhere in this special section. Following our analysis, three features are characteristic of the mix of formal and informal recursivity in stewardship processes: rhetorical openness, self-selection and decision-making opacity. In the case of CC, rhetorical openness means that without formal rules of inclusion and exclusion in discussions on mailing lists or platforms, the organization is in principle open to feedback from literally anyone. This feature is regularly substantiated rhetorically by CC headquarters' calls for participation. The flipside of openness is self-selection as the most important criterion for actual involvement in recursive processes. While such informal feedback allows CC to further develop its licenses together with various legitimacy communities, the participants represent individual views that might not be shared by all members of their communities. While self-selection is not unknown to membership organizations, it can be addressed more comprehensively by their statutes and voting rules. The Achilles' heel of stewardship organizations remains decision-making accountability. In the case of CC, informal feedback may be provided and accessed by anyone, but decision-making and rule revision are undertaken by the board and staff at the headquarters based on the discretion formally granted by the organization's legal statutes but perceived as top-down and opaque by its legitimacy communities.

While informality in collecting feedback may help increase participation in recursive episodes, formal forms of recursivity, such as official explanation of decisions and the creation of transparent rules for decision-making processes, may be necessary in order to reach out to additional legitimacy communities. Given that mailing lists, blogs and other online platforms are increasingly used - but rarely studied - the potential drawbacks of informal feedback in recursive standard-setting episodes are also relevant to other non-membership stewardship organizations.

\section{Conclusion}

While formal recursive rule-setting procedures are increasingly being studied, less is known about how informal feedback is collected and integrated by transnational standard-setters, particularly when their standards are addressed to globally dispersed users. In this article, we have analyzed regulatory conversations between Creative Commons, an organization that developed the most widely used open content licenses for digital content, and its emerging user communities. The empirical results of our case study are of wider empirical and theoretical relevance. They contribute to our understanding of how private standard-setting organizations concerned with reducing the uncertainty that threatens the broad application of their standards can gather informal feedback from standard users. By organizing regulatory conversations on mailing lists, standard-setters can learn from the practical experiences of their users. At the same time, they need to be prepared to address issues 
of self-selection, decision-making opacity and a perceived lack of accountability. We have found that informal regulatory conversations, if widely diffused, are likely to give rise to legitimacy communities that articulate demands.

While our study reveals the relevance of informal feedback for understanding the recursivity of transnational standard-setting, the question of the generalizability of our results remains. This study is therefore a call for more research on the interplay of informal and formal feedback in a broader range of standard-setting organizations. Such a research agenda appears promising and relevant because of the rising number and importance of non-membership organizations that claim to provide a public good in transnational governance, as well as the rapid spread of online-based consultation procedures in transnational standard-setting more broadly.

\section{Note}

We thank two anonymous reviewers for their helpful comments, Terrance Halliday, Jonathan Zeitlin and the participants of a panel discussion at the SASE Annual Meeting in Chicago 2014 for feedback on an earlier version of this paper. We also thank Leonie Eland for her assistance in coding Brazilian mailing lists.

\section{References}

Anheier, H. and Themudo, N. (2002) 'Organizational Forms of Global Civil Society: Implications of Going Global', in H. Anheier, M. Glasius and M. Kaldor (eds.), Global Civil Society Yearbook 2002. Oxford: Oxford University Press, pp. 191-216.

Archibugi, D. and Filippetti, A. (2010) 'The Globalisation of Intellectual Property Rights: Four Learned Lessons and Four Theses', Global Policy, 1 (2), pp. 137-149.

Bartley, T. (2007) 'Institutional Emergence in an Era of Globalization: The Rise of Transnational Private Regulation of Labor and Environmental Conditions', American Journal of Sociology, 113 (2), pp. 297-351.

Bartley, T. (2011) 'Transnational Governance as the Layering of Rules: Intersections of Public and Private Standards', Theoretical Inquiries in Law, 12 (2), pp. 517-542.

Black, J. (2002) 'Regulatory Conversations', Journal of Law and Society, 29 (1), pp. 163-196.

Black, J. (2008) 'Constructing and Contesting Legitimacy and Accountability in Polycentric Regulatory Regimes', Regulation and Governance, 2, pp. 137-164.

Braithwaite, J. (2002) 'Rules and Principles: A Theory of Legal Certainty', Australian Journal of Legal Philosophy 27, pp. 47-82.

Botzem, S. and Dobusch, L. (2012) 'Standardization Cycles: A Process Perspective on the Formation and Diffusion of Transnational Standards', Organization Studies, 33 (5-6), pp. 735-760.

Brunsson, N., Jacobsson, B. and Associates (Eds.) (2000) A World of Standards. Oxford: Oxford University Press.

Büthe, T. and Mattli, W. (2011) The Global Rulers. Princeton, NJ: Princeton University Press.

Calliess, G.-P. and Zumbansen, P. (2010) Rough Consensus and Running Code. Oxford: Hart Publishing.

CC (Creative Commons) (n.d.a) 'History' [online]. Available from: https:// wiki.creativecommons.org/wiki/History [Accessed 29 December 2016].

CC (Creative Commons) (n.d.b) '4.0/NonCommercial' [online]. Available from: https://wiki.creativecommons.org/wiki/4.0/NonCommercial [Accessed 29 December 2016].
CC (Creative Commons) (2002) 'Legal Code. Attribution-NonCommercial 1.0' [online]. Available from: https://creativecommons.org/licenses/ by-nc/1.0/legalcode [Accessed 29 December 2016].

CC (Creative Commons)/Brown (2004) 'Announcing (and explaining) our new 2.0 licenses' [online]. Available from: https://creativec ommons.org/2004/05/25/announcingandexplainingournew20licenses/ [Accessed 29 December 2016].

CC (Creative Commons) (2006) 'Proposed Best Practice Guidelines to Clarify the Meaning of "NonCommercial" in the Creative Commons Licenses' [online]. Available from: http://lists.ibiblio.org/pipermail/cclicenses/attachments/20060110/02d7a271/attachment.pdf [Accessed 10 September 2013].

CC (Creative Commons) (2009) 'Defining Noncommercial. Full report and all appendices' [online]. Available from: http://mirrors.creativec ommons.org/defining-noncommercial/Defining_Noncommercial_full report.pdf [Accessed 12 April 2011].

CC (Creative Commons) (2013) 'MOU (Memorandum of Understanding)' [online]. Available from: http://wiki.creativecommons.org/index.php? title=MOU\&oldid=85919 [Accessed 19 August 2015].

CC (Creative Commons)/Walsh (2013) 'Commercial Rights Reserved proposal outcome: no change' [online]. Available from: http://crea tivecommons.org/weblog/entry/36725 [Accessed 3 January 2017].

CC (Creative Commons) (2016) 'Team' [online]. Available from: https:// creativecommons.org/staff [Accessed 3 October 2016).

CC (Creative Commons) (2017) 'License Versions' [online]. Available from: https://wiki.creativecommons.org/wiki/License_Versions [Accessed 18 July 2017].

Dingwerth, K. (2008) 'Private Transnational Governance and the Developing World: A Comparative Perspective', International Studies Quarterly, 52 (3), pp. 607-634.

Djelic, M.-L. and Sahlin-Andersson, K. (2006) Transnational Governance. Cambridge: Cambridge University Press.

Dobusch, L. (2013) 'CC Global Summit 2011 \#1: The End of the Porting Experiment?' in L. Dobusch, P. Mader and S. Quack (eds.), Governance across Borders: Transnational Fields and Transversal Themes. Berlin: epubli, pp. 181-183.

Dobusch, L. and Kapeller, J. (2012) 'Regulatorische Unsicherheit und private Standardisierung: Koordination durch Ambiguität', Managementforschung, 22, pp. 43-81.

Dobusch, L. and Quack, S. (2010) 'Epistemic communities and social movements: Transnational dynamics in the case of creative commons', in M.-L. Djelic and S. Quack (eds.) Transnational Communities: Shaping Global Governance. Cambridge: Cambridge University Press, pp. 226-251.

Dobusch, L. and Quack, S. (2013) 'Framing Standards, Mobilizing Users: Copyright versus Fair Use in Transnational Regulation', Review of International Political Economy 20 (1), pp. 52-88.

Dulong de Rosnay, M. (2009) 'Creative commons licenses legal pitfalls: Incompatibilities and solutions' [online]. Available from: https://hal. archives-ouvertes.fr/file/index/docid/671622/filename/101220cc_inc ompatibilityfinal.pdf [Accessed 18 April 2017].

Flyvbjerg, B. (2006) 'Five Misunderstandings About Case-Study Research', Qualitative Inquiry, 12 (2), pp. 219-245.

Freeman, J. (1972-73): The Tyranny of Structurelessness. Berkeley Journal of Sociology, 17, pp. 151-164.

Garsten, C. and Jacobsson, K. (2011) 'Transparency and Legibility in International Institutions: The UN Global Compact and Post-political Global Ethics', Social Anthropology, 19 (4), pp. 378-393.

Gasser, U., Budish, R. and West, S. M. (2015) 'Multistakeholder as Governance Groups: Observations from case studies', Berkman Center Research Publication, No. 2015-1.

Guo, L., Tan, E., Chen, S., Zhang, X. and Zhao, Y. E. (2009) 'Analyzing Patterns of User Content Generation in Online Social Networks', proceedings of the 15th ACM SIGKDD international conference on Knowledge discovery and data mining held in Paris, June 28 - July 2009, pp. 369-378. 
Hahn, R. and Weidtmann, C. (2016) 'Transnational Governance, Deliberative Democracy, and the Legitimacy of ISO 26000: Analyzing the Case of a Global Multistakeholder Process', Business \& Society, 55 (1), pp. 90-129.

Halliday, T. C. and Carruthers, B. G. (2007) 'The Recursivity of Law: Global Norm Making and National Lawmaking in the Globalization of Corporate Insolvency Regimes', American Journal of Sociology, 112 (4), pp. 1135-1202.

Halliday, T. C. and Carruthers, B. G. (2009) Bankrupt. Stanford, CA: Stanford University Press.

Halliday, T. C. and Shaffer, G. (eds.) (2015) Transnational Legal Orders. Cambridge: Cambridge University Press.

Lang, M. (2011) 'Transnationale Governance vor nationalen Herausforderungen' Unpublished Diploma Thesis, Department of Political Science. Otto-Friedrich-Universität Bamberg.

Morando, F. (2014) 'Creative Commons' [online]. Available from: https://publixphere.net/i/noc/page/IG_Case_Study_Creative_Commons [Accessed 18 April 2017].

Rose, C, (2014) 'Surprising Commons', BYU Law Review, 6, pp. $1257-$ 1282.

Suchman, M. C. (1995) 'Managing Legitimacy: Strategic and Institutional Approaches', Academy of Management Review, 20 (3), pp. 571-610.

Ortmann, G. (2010) 'On Drifting Rules and Standards', Scandinavian Journal of Management, 26, pp. 204-214.

Van Eechoud, M. and Van Der Wal, B. (2008). 'Creative Commons Licensing for Public Sector Information. Opportunities and Pitfalls' [online]. Available from: https://papers.ssrn.com/sol3/papers.cfm? abstract_id=1096564 [Accessed 29 December 2016].

Yin, R. K. (1994) Case Study Research. Thousand Oaks, CA: Sage Publications.

\section{Author Information}

Leonhard Dobusch is Professor of Business Administration with a focus on Organization at the University of Innsbruck. He holds degrees in Law and in Business Studies and his main research interests include the management of digital communities and private regulation via standards, specifically in the field of copyright.

Markus Lang is a research assistant at the Max Weber Institute for Sociology in Heidelberg. His main areas of interest are in the sociology of law and professions theory. He is currently finishing a dissertation that shows how information specialists made transnational patent protection more attractive.

Sigrid Quack is Professor of Sociology with a focus on comparative and transnational perspectives at the University of Duisburg-Essen. She is a Senior Research Fellow at the Centre for Global Cooperation Research and a member of the Research Priority Area Transformation of Contemporary Society. Her main research interests encompass globalization, cross-border standard-setting and the role of professional expertise in transnational governance. 